\title{
Sistemas integrados de gestão ambiental, segurança e saúde ocupacional: uma diretriz para implantação das brigadas de incêndio em plantas industriais
}

Wilson Pimenta da Silva D'Ávila wilson.davila@ifes.edu.br

instituto Federal de Educação, Ciência e Tecnologia do Espírito Santo (IFES), ES,
Brasil

Tântalo Almeida de Oliveira Campos

tantalojf@hotmail.com Petróleo Brasileiro S.A. (PETROBRAS), Espírito Santo, Brasil

\section{RESUMO}

Em estabelecimentos industriais existe uma diversidade de operações que podem levar à ocorrência de eventos com consequências indesejáveis para o meio ambiente, trabalhadores e sociedade. Nesse sentido, a necessidade de garantir a segurança dos processos produtivos, dentre outras necessidades, tem levado à adoção de Sistemas Integrados de Gestão Ambiental, Segurança e Saúde Ocupacional e, consequentemente, à implantação das brigadas de incêndio. Organizar uma brigada constitui uma tarefa complexa, pois a Norma NBR 14276 da Associação Brasileira de Normas Técnicas não faz referência às Normas Regulamentadoras (NR) da Secretaria de Trabalho do Ministério da Economia, exceção à NR 6 - Proteção Individual, ficando por conta de cada profissional perceber as interfaces normativas que precisam ser consideradas. Assim, esta pesquisa teve como objetivo apresentar uma diretriz para implantação das brigadas de incêndio em plantas industriais, sem contudo esgotar o assunto. A NBR 14276 foi analisada e tomada como base para construção da diretriz. Uma análise exploratória das Normas Regulamentadoras foi realizada com vistas a identificar os aspectos normativos que possam interferir na implantação e/ou atuação das brigadas de incêndio. Assim, foi verificado que A NBR 14276 e a NBR 15219 constituem os principais instrumentos normativos a serem utilizados para implantação das brigadas de incêndio, todavia, se as Normas Regulamentadoras não forem consideradas, algumas lacunas técnico-normativas poderão comprometer a atuação das equipes de resposta. A diretriz elaborada, composta por três procedimentos, atende ao objetivo proposto, porém apresenta algumas limitações devido à complexidade e à extensão do tema.

PALAVRAS-CHAVE: Norma Regulamentadora. Plano de emergência. Análise de risco. 


\section{INTRODUÇÃO}

Em estabelecimentos industriais existe uma diversidade de operações que podem levar à ocorrência de eventos com consequências indesejáveis para o meio ambiente e para os trabalhadores, nesse sentido, garantir a segurança dos processos produtivos, com menores impactos internos e externos, tem se tornado uma das metas assumidas pelas organizações e tem levado à adoção de Sistemas Integrados de Gestão Ambiental, Segurança e Saúde Ocupacional. Assim, diversas ações têm sido realizadas para responder imediatamente a qualquer evento que coloque em risco o meio ambiente, a vida ou o patrimônio, dentre elas, a implantação das brigadas de incêndio, que são definidas como:

Grupo organizado de pessoas preferencialmente voluntárias ou indicadas, treinadas e capacitadas para atuar na prevenção e no combate ao princípio de incêndio, abandono de área e primeiros socorros, dentro de uma área preestabelecida na planta (ASSOCIAÇÃO BRASILEIRA DE NORMAS TÉCNICAS, 2006, p. 2).

Estes grupos, ou equipes, são formados por trabalhadores que, diante de situações adversas, precisam atuar de forma coordenada e assertiva, constituindo uma das mais importantes medidas de prevenção contra incêndio (ALMEIDA e FRANCOSO, 2015; SILVA, CARMO e SANTOS, 2018; MENDES e TEIXEIRA, 2017). Nesse sentido, Camillo Júnior e Leite (2008) chamam atenção para o fato de que o corpo de bombeiros não consegue estar presente em todos os locais, daí a importância de orientações normativas para a formação das brigadas de incêndio. Diante do exposto, cabe ainda considerar que:

Incêndios, explosões e a poluição ao meio ambiente são uns dos mais sérios e, na maioria das vezes, imprevisíveis eventos que afetam a vida, missão e objetivos da indústria de processamento, desde meados do século XIX. Ainda hoje, eles continuam a ocorrer, sendo o seu impacto econômico crescente (DUARTE et al., 2008, p. 380)

Contudo, organizar uma brigada de incêndio constitui uma tarefa complexa, pois o principal documento de referência, a Norma Brasileira NBR 14276: Brigada de incêndio, da Associação Brasileira de Normas Técnicas (2006), não faz referência às Normas Regulamentadoras (NR) da Secretaria de Trabalho do Ministério da Economia, exceção à NR 6 - Proteção Individual (BRASIL, 2018a). Desse modo, fica por conta de cada profissional perceber as interfaces normativas e, dessa forma, informações relevantes poderão passar despercebidas e comprometer a estruturação e a atuação das brigadas.

Assim, considerando que a preparação para o atendimento à emergência constitui um dos requisitos dos sistemas integrados de gestão ambiental e segurança ocupacional, esta pesquisa teve como objetivo apresentar uma diretriz para implantação das brigadas de incêndio em plantas ${ }^{1}$ industriais, sem contudo esgotar 0 assunto. 
${ }^{1}$ Planta é um local onde estão situadas uma ou mais edificações ou área a ser utilizada para -um evento ou ocupação (ASSOCIAÇÃO BRASILEIRA DE NORMAS TÉCNICAS, 2006, p.3).

\section{REFERENCIAL TEÓRICO}

A adoção de sistemas de gestão tem se tornado uma importante estratégia para promover a melhoria nos processos produtivos em vários aspectos, dentre eles, os que se referem à proteção dos trabalhadores e do meio ambiente. Todavia, estudos tem demonstrado que sistemas de gestão implantados separadamente podem ser menos eficientes do que sistemas implantados em conjunto, ou seja, de modo integrado (POLTRONIERI, GEROLAMO, CARPINETTI (2015). Nesse aspecto, é possível verificar que:

múltiplos sistemas de gestão são ineficientes, difíceis de administrar e difícil de obter o efetivo envolvimento das pessoas. Portanto é muito mais simples obter a cooperação dos funcionários para um único sistema do que para três sistemas independentes. Esse fato proporciona as organizações atingir melhores níveis de desempenho a um custo global muito menor (PETER FILHO, 2018, p.1545).

Embora exista uma grande preocupação no que se refere à diminuição dos custos nas empresas, essa não é a única. Atualmente crescem as preocupações relacionadas com a responsabilidade social e ambiental, o que inclui a segurança e o meio ambiente, exigindo das empresas posturas cada vez mais sustentáveis em relação aos seus processos (SEIFFERT, 2010). Quanto aos aspectos ambientais, por exemplo, verifica-se que:

a preocupação ambiental vem chamando cada vez mais a atenção da população em geral e muitas empresas buscam a melhoraria da sua imagem junto a esse público, uma vez que consumidores passam a optar por produtos e por serviços com menor impacto ambiental negativo ao invés daqueles que podem prejudicar a saúde e o meio ambiente (KREUZ E FROEHLICH, 2018, p.63).

Nas operações industriais, com frequência, são gerados riscos físicos, químicos, mecânicos, dentre outros, e isso ocorre por diversos fatores, dentre estes, as operações de armazenamento, transferência, transformação e utilização dos diversos materiais, que se apresentam em diferentes estados físicos e com propriedades intrínsecas muito diversificadas. Nesse complexo ambiente industrial, podem surgir diferentes cenários de emergência, capazes de atingir trabalhadores próximos e/ou até mesmo extrapolar os limites da unidade fabril.

Diante dessa perspectiva, as normas que tratam dos Sistemas de Gestão Ambiental e dos Sistemas de Gestão de Segurança e Saúde Ocupacional, respectivamente, possuem diretrizes em comum, dentre elas, a preparação para o atendimento à emergência. Quanto à classificação dos possíveis impactos de uma emergência, Seiffert (2010) coloca que quando um evento provoca impacto dentro dos limites da instalação industrial, esse pode ser referido como de um impacto de abrangência ocupacional, mas quando extrapola esses limites passa a ser ambiental. 
Acompanhando esse conceito, uma emergência ambiental pode surgir como uma emergência de âmbito ocupacional. Nesse aspecto, não há o que se falar em preparação para emergência ambiental ou ocupacional, mas apenas em preparação para atendimento à emergência; nesse sentido, verifica-se que:

a Brigada de Emergência reduz ao mínimo o potencial de eventos catastróficos nas operações industriais, sejam incêndios, derramamento de produto químico ou explosões (PACO e MOREIRA, 2016, p.4).

As equipes de brigadas, portanto, são formadas para atenderem simultaneamente aos requisitos normativos de natureza ambiental e ocupacional (SEIFERT, 2010). Os estudos de Kreuz e Froehlich (2018), Amorim, Librelotto e Ferroli (2015), por exemplo, permitem identificar a existência de ações relacionadas à preparação para atendimento à emergência por parte de brigadas de incêndio dentro de um Sistema de Gestão Ambiental.

No Brasil, a implantação de uma brigada de incêndio deve necessariamente considerar a NBR 14276 - Brigada de incêndio da Associação Brasileira de Normas Técnicas (2006) e a NBR 15219 - Plano de emergência contra incêndio da Associação Brasileira de Normas Técnicas (2005). Além disso, os instrumentos normativos dos Estados/Distrito Federal, tal como a Norma Técnica 07 no Estado do Espírito Santo, também precisam ser observados (ESPÍRITO SANTO, 2016). As Normas Regulamentadoras apresentam aspectos normativos importantes que, para serem evidenciados, necessitam de uma análise exploratória mais específica.

\section{MATERIAIS E MÉTODOS}

Para atingir o objetivo, esta pesquisa foi realizada através de uma abordagem qualitativa, teórica-conceitual que compreendeu um levantamento bibliográfico para subsidiar uma revisão sobre o tema e a construção de um referencial teórico. Foram identificadas duas normas que, em conjunto, estabelecem a linha mestra no que se refere a implantação da brigada de incêndio: NBR 14276 e NBR 15219.

Face a necessidade de realizar um estudo cujo resultado deverá ser abrangente, ou seja, capaz de contribuir com profissionais e pesquisadores situados em qualquer parte do território brasileiro, normas estaduais não foram objeto de análise exploratória e, desse modo, alguns itens oriundos de legislação estadual foram utilizados apenas permitir uma melhor compreensão do tema.

A NBR 14276 foi analisada e tomada como base para construção da diretriz para implantação das brigadas de incêndio em plantas industriais. Uma análise exploratória das Normas Regulamentadoras foi realizada com vistas a identificar os aspectos normativos que possam interferir, direta ou indiretamente, na implantação e/ou atuação assertiva das brigadas de incêndio.

Considerando a diversidade de processos produtivos, tais como petróleo, mineração, dentre outros, foram analisadas apenas as Normas Regulamentadoras que apresentam aplicabilidade comum à maioria das plantas industriais, ou seja, normas específicas não foram objeto de análise exploratória. Assim, das 37 Normas Regulamentadoras existentes, 23 foram analisadas. 
Quando constatada a existência de muitos aspectos normativos capazes interferir na implantação e/ou atuação assertiva das brigadas de incêndio, apenas alguns destes foram trazidos ao corpo do texto deste trabalho. Essa medida foi necessária face à extensão e complexidade do assunto tratado. Como resultado, foram elaborados três procedimentos que, em conjunto, formam a diretriz para implantação das brigadas de incêndio em plantas industriais.

\section{RESULTADOS E DISCUSSÃO}

\section{PROCEDIMENTO - DEFINIÇÃO DA COMPOSIÇÃO E DO ORGANOGRAMA}

Segundo a NBR 14276, a estruturação da equipe de brigada tem como ponto de partida a escolha de um responsável pela brigada de incêndio da planta, trata-se do próprio responsável pela ocupação da planta, ou quem ele designar por escrito (ASSOCIAÇÃO BRASILEIRA DE NORMAS TÉCNICAS, 2006). Para atender a esse requisito, é possível, por exemplo, que algum dos profissionais dos Serviços Especializados em Engenharia de Segurança e em Medicina do Trabalho - SESMT - quando existentes, sejam escolhidos, tendo em vista que:

As atividades dos profissionais integrantes dos Serviços Especializados em Engenharia de Segurança e em Medicina do Trabalho são essencialmente prevencionistas, embora não seja vedado o atendimento a emergência (BRASIL, 2016a, p. 4).

Compete ainda ao responsável pela brigada de incêndio da planta dimensionar a equipe. $O$ dimensionamento deve ser realizado por compartimento, pavimento ou setor levando em consideração o grau de risco de ocupação da planta (Tabela 1) e sua população fixa ${ }^{2}$. Estas duas variáveis serão os parâmetros de entrada da Tabela 2 (ASSOCIAÇÃO BRASILEIRA DE NORMAS TÉCNICAS, 2006).

Tabela 1 - Cargas de incêndio específicas (Qfi) por ocupação

\begin{tabular}{|c|c|c|c|}
\hline Ocupação & Descrição & Qfi $\left(\mathrm{MJ} / \mathrm{m}^{2}\right)$ & Grau de Risco \\
\hline \multirow{5}{*}{ Industrial } & Chocolate & 400 & Médio \\
\hline & Motores elétricos & 300 & Baixo \\
\hline & Papel (preparo da celulose) & 80 & Baixo \\
\hline & Roupas & 500 & Médio \\
\hline & Tintas e solventes & 4000 & Alto \\
\hline
\end{tabular}

Fonte: Adaptado de Associação Brasileira de Normas Técnicas (2006) 
Tabela 2 - Composição da brigada de incêndio por pavimento ou compartimento

\begin{tabular}{|c|c|c|c|c|c|c|c|}
\hline \multirow{2}{*}{ Grupo } & \multirow{2}{*}{$\begin{array}{c}\text { Grau de } \\
\text { Risco }\end{array}$} & \multicolumn{6}{|c|}{ População fixa por pavimento ou compartimento } \\
\hline & & Até 2 & Até 4 & Até 6 & Até 8 & Até 10 & $>10$ \\
\hline \multirow{3}{*}{ 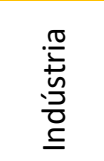 } & Baixo & 1 & 2 & 2 & 2 & 2 & Nota $^{3}$ \\
\hline & Médio & Todos & Todos & 4 & 5 & 6 & Nota $^{3}$ \\
\hline & Alto & Todos & Todos & Todos & 7 & 8 & Nota $^{3}$ \\
\hline
\end{tabular}

Fonte: Adaptado de Associação Brasileira de Normas Técnicas (2006)

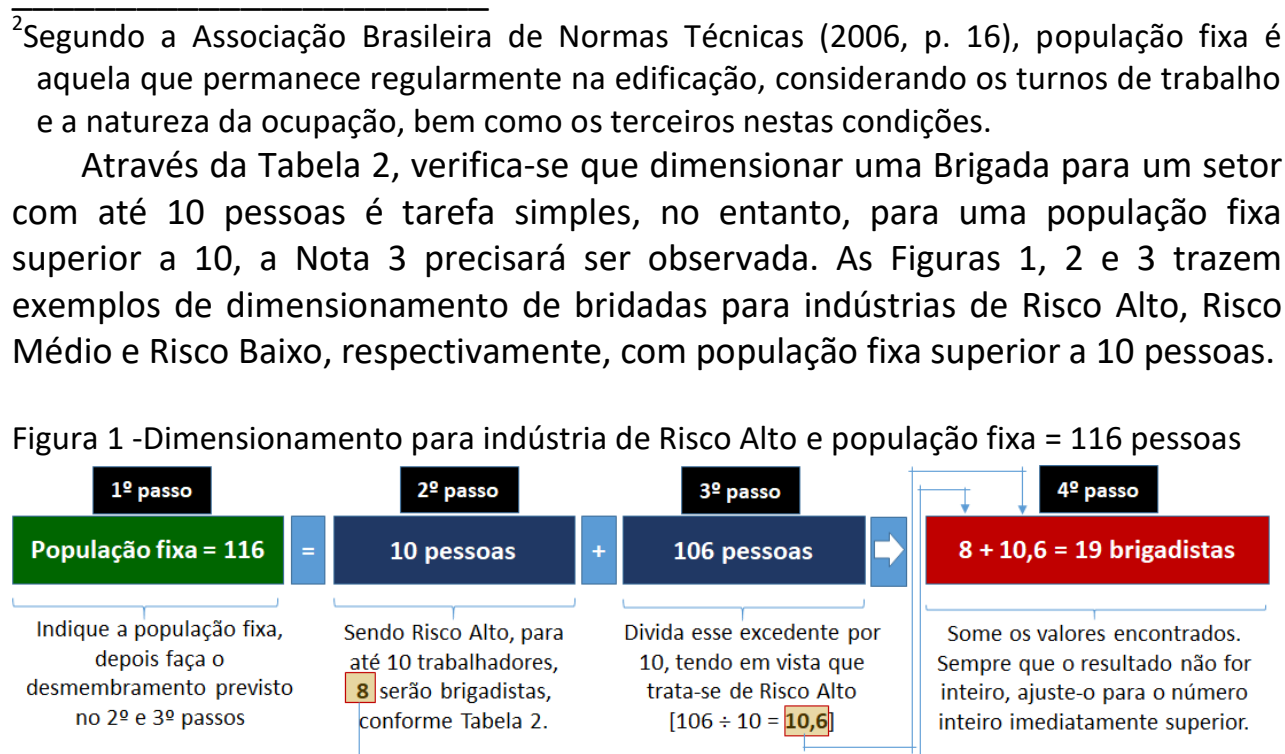

Fonte: Organizado pelos autores

Figura 2 -Dimensionamento para indústria de Risco Médio e população fixa $=259$ pessoas

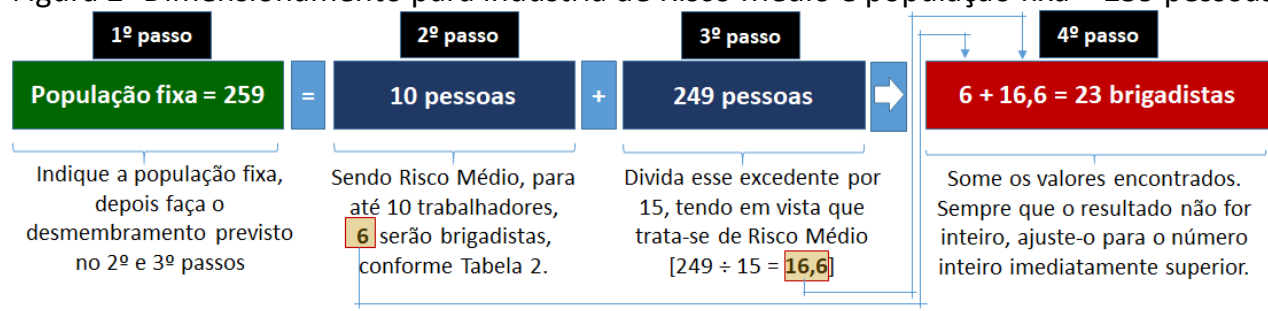

Fonte: Organizado pelos autores

Figura 3 -Dimensionamento para indústria de Risco Baixo e população fixa $=44$ pessoas

\begin{tabular}{|c|c|c|c|}
\hline 19 passo & $2^{2}$ passo & 39 passo & $4^{\circ}$ passo \\
\hline População fixa = 44 & 10 pessoas & 34 pessoas & $2+1,7=4$ brigadistas \\
\hline $\begin{array}{c}\text { Indique a população fixa, } \\
\text { depois faça o } \\
\text { desmembramento previsto } \\
\text { no } 2^{\circ} \text { e } 3 \text { passos }\end{array}$ & $\begin{array}{l}\text { Sendo Risco Baixo, para } \\
\text { até } 10 \text { trabalhadores, } \\
2 \text { serão brigadistas, } \\
\text { conforme Tabela } 2 .\end{array}$ & $\begin{array}{l}\text { Divida esse excedente por } \\
20 \text {, tendo em vista que } \\
\text { trata-se de Risco Médio } \\
{[34 \div 20=1,7]}\end{array}$ & $\begin{array}{l}\text { Some os valores encontrados. } \\
\text { Sempre que o resultado não for } \\
\text { inteiro, ajuste-o para o número } \\
\text { inteiro imediatamente superior. }\end{array}$ \\
\hline
\end{tabular}

Fonte: Organizado pelos autores 
Outros exemplos de dimensionamento podem ser encontrados na NBR 14276 (ASSOCIAÇÃO BRASILEIRA DE NORMAS TÉCNICAS,2006). Cabe ao responsável pela brigada de incêndio ficar atento às flutuações da população fixa na planta, devendo realizar os ajustes necessários.

\footnotetext{
${ }^{3}$ Segundo a Associação Brasileira de Normas Técnicas quando ultrapassar 10 pessoas deve-se acrescentar +1 brigadista para cada grupo de até 20 pessoas para risco baixo, mais um brigadista para cada grupo de até 15 pessoas para risco médio e mais 1 brigadista para cada grupo de até 10 pessoas para risco alto (ASSOCIAÇÃO BRASILEIRA DE NORMAS TÉCNCAS, 2006, p. 16).
}

Terminado o dimensionamento, é necessário que o responsável pela brigada de incêndio da planta estabeleça o organograma da brigada de incêndio e, nesse aspecto, a NBR 14276 coloca vários exemplos (ASSOCIAÇÃO BRASILIERA DE NORMAS TÉCNICAS, 2006). Guardada a importância de cada um dos membros, cabe destacar a função coordenador geral da brigada, tendo em vista que este:

É o brigadista responsável pela coordenação e execução das ações de emergência de todas as edificações que compõem uma planta, independentemente do número de turnos (ASSOCIAÇÃO BRASILEIRA DE NORMAS TÉCNICAS, 2006, p. 2).

É a autoridade máxima na empresa no caso de ocorrência de uma situação real ou simulado de emergência, devendo ser uma pessoa com capacidade de liderança, com respaldo da direção da empresa ou que faça parte dela (ASSOCIAÇÃO BRASILEIRA DE NORMAS TÉCNICAS, 2006, p. 4).

Imediatamente abaixo do coordenador geral existe outras duas lideranças: o chefe da edificação/turno e o líder de setor. Segundo a NBR 14276, o chefe da edificação, ou do turno, é um brigadista responsável pela coordenação e execução das ações de emergência de uma determinada edificação da planta; o líder de setor é um brigadista responsável pela coordenação e execução das ações de emergência de um determinado setor/compartimento/pavimento da planta. Sob o comando de um Líder existem os demais brigadistas, tal como pode ser observado no organograma da Figura 4 (ASSOCIAÇÃO BRASILEIRA DE NORMAS TÉCNICAS, 2006).

Figura 4 -Exemplo de organograma da brigada de uma planta com duas edificações

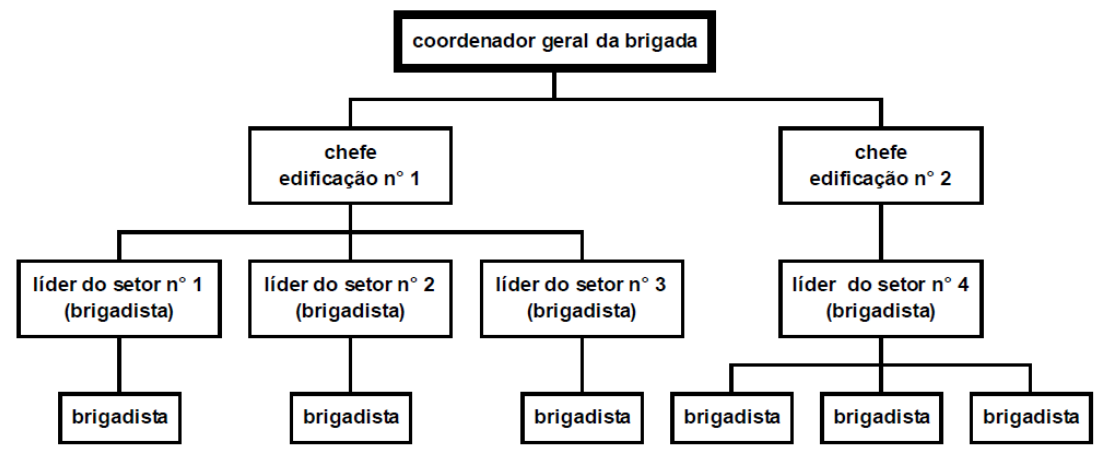

Fonte: Associação Brasileira de Normas Técnicas (2006) 


\section{2o PROCEDIMENTO - SELEÇÃO, TREINAMENTO E PLANEJAMENTO DA ATUAÇÃO}

A NBR 14276 dispõe que a brigada é composta por um grupo de pessoas preferencialmente indicadas ou voluntárias. Quanto aos critérios de seleção, os candidatos a brigadistas devem ser selecionados atendendo ao maior número de critérios, dentre eles: permanecer na edificação durante seu turno de trabalho, possuir boa condição física e boa saúde, possuir bom conhecimento das instalações, ter mais de 18 anos, ser alfabetizado (ASSOCIAÇÃO BRASILEIRA DE NORMAS TÉCNICAS, 2006).

Cabe destacar que a boa condição física e boa saúde deve ser verificada por um médico, conforme previsto na NR 7 - Programa de Controle Médico de Saúde Ocupacional (BRASIL, 2018b). É preciso ainda considerar que, além de esforço físico intenso, em situações de treinamentos/simulados (Figura 5), os brigadistas poderão ficar expostos a situações de risco e ambientes bem diferentes das situações cotidianas, tais como altura ou espaços confinados.

Figura 5 - Treinamento de resgate em espaço confinado

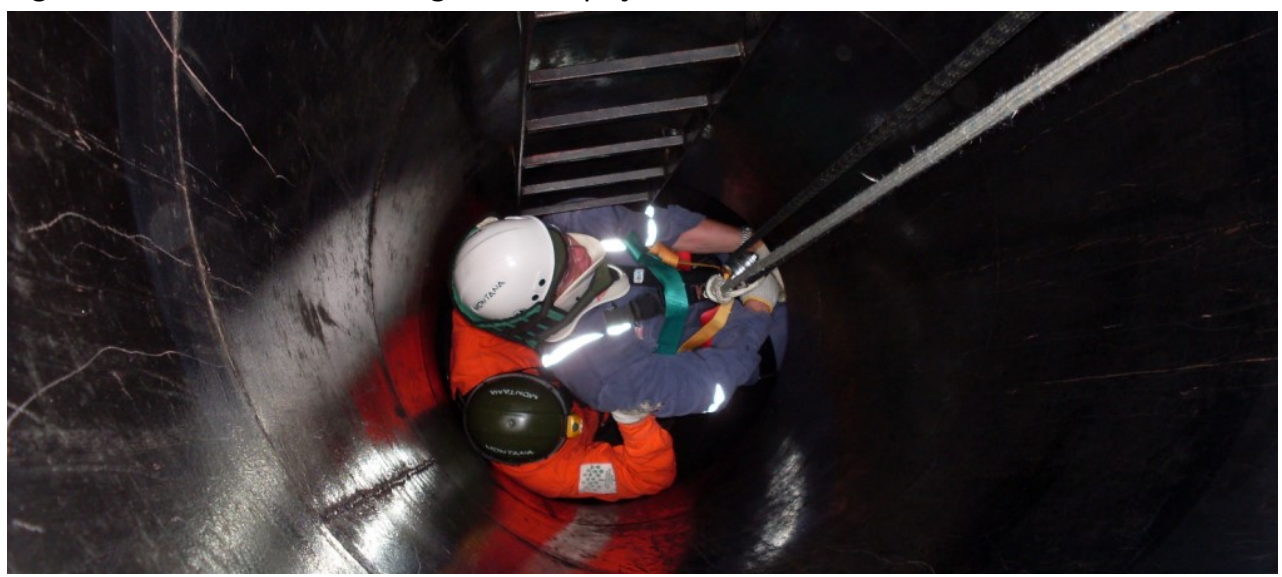

Fonte: Banco de dados do grupo de pesquisa

Assim, a título de exemplo, as normas NR 33 que trata da Segurança e Saúde no Trabalhos em Espaços Confinados (BRASIL, 2012), a NR 35, que regulamenta o Trabalho em Altura (BRASIL, 2016c) e a NR 20 que trata da Segurança e Saúde no Trabalho com Inflamáveis e Combustíveis (BRASIL, 2018f), determinam que as pessoas que executam salvamento nessas condições devem possuir aptidão física e mental compatível com a atividade a desempenhar.

Diante do exposto, recomenda-se que o responsável pela brigada de incêndio da planta divulgue um edital interno, informando as atividades dos brigadistas, os riscos a que estarão expostos e os critérios que serão adotados para seleção, dentre outros. Uma vez selecionados, os futuros brigadistas deverão passar por um treinamento inicial - teórico e prático - sobre combate a incêndio, abandono de área e primeiros socorros.

Embora a Associação Brasileira de Normas Técnicas (2006) estabeleça

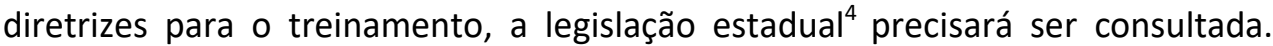
Verifica-se que 0 treinamento inicial estabelece apenas uma primeira aproximação teórica e prática para atuação, no entanto, não responde em totalidade à complexidade das plantas de processo, visto que, estas apresentam 
riscos e situações muito específicas, capazes de gerar diferentes cenários emergenciais

\begin{abstract}
${ }^{4}$ No Estado do Espírito Santo, por exemplo, os brigadistas devem passar por treinamento específico - Curso de Formação de Brigadistas Eventuais - CFBE - que somente poderá ser ministrado por uma Empresa Especializada na Formação e Treinamento após autorização do Centro de Ensino e Instrução de Bombeiros - CEIB, ou pelo próprio CBMES. A avaliação dos cursandos é de competência exclusiva do CBMES. A avaliação dar-se-á através de exame teórico em que serão considerados aprovados todos os cursandos com nota final igual ou superior a 7,00 (sete) e que tenham frequência de $100 \%$ (cem por cento) da carga horária do curso (20h). O curso terá validade de 1 ano com reciclagem de 12 horas (ESPÍRITO SANTO, 2016).
\end{abstract}

Assim, torna-se importante considerar que:

A tendência atual é que o corpo de bombeiros e os órgãos reguladores das brigadas de combate a incêndios estabeleçam somente critérios básicos para a formação, deixando para o responsável pela ocupação da área definir, de acordo com os riscos existentes, qual seria a sua melhor composição da brigada e qual a qualificação mínima de seus membros (CAMILLO JÚNIOR E LEITE, 2008, p. 288).

Face ao exposto, após seleção e treinamento inicial, a brigada deverá atuar em conformidade com o plano de emergência da planta, estabelecido de acordo com a NBR 15219 (ASSOCIAÇÃO BRASILEIRA DE NORMAS TÉCNICAS, 2005), pois, em síntese, é a partir do reconhecimento dos cenários emergenciais de cada planta que ocorrerá a definição de toda a estratégia de ação, que se refere, dentre outros aspectos, aos procedimentos de atuação, aos materiais de contenção e às habilidades da equipe. Assim, para uma atuação assertiva, faz-se necessário que todas as ações da brigada caminhem em consonância com o plano de emergência.

Além dos aspectos normativos discutidos anteriormente, ainda existem outros que também precisam ser considerados. A NR 1 - Disposições Gerais, determina que o empregador deve informar aos trabalhadores os riscos profissionais e os meios para prevenir e limitar tais riscos (BRASIL, 2009). Esses meios de proteção dos trabalhadores, inclusive os que fazem parte das brigadas, são comumente estabelecidas a partir dos SESMT, que se encontram diretamente envolvidos na elaboração dos planos de emergência, visto que:

a elaboração de planos de controle de efeitos de catástrofes, de disponibilidade de meios que visem ao combate a incêndios e ao salvamento e de imediata atenção à vítima deste ou de qualquer outro tipo de acidente estão incluídos em suas atividades (BRASIL, 2016a, p. 4).

Conforme a NR 5 - Comissão Interna de Prevenção de Acidentes, a CIPA tem por atribuição, dente outras, participar da implementação do controle da qualidade das medidas de prevenção implantadas, além de promover o cumprimento das Normas Regulamentadoras (BRASIL, 2011a). Nesse sentido, é importante que a atuação das brigadas esteja articulada com as atividades da CIPA, visto que, as ações de prevenção também fazem parte das atividades dos brigadistas (ASSOCIAÇÃO BRASILEIRA DE NORMAS TÉCNICAS, 2006). 
Os treinamentos precisam considerar, dentre outros, que um abandono de área poderá ser necessário. Embora a paralisação das atividades diante de situação de grave e iminente risco esteja prevista na NR 9 - Programa de Prevenção de Riscos Ambientais (BRASIL, 2017), e em outras normas regulamentadoras, é necessária uma ampla discussão com - e entre - os trabalhadores para que estes ajam segundo as orientações fornecidas em treinamentos/simulados, pois:

normalmente, as pessoas demoram a reagir diante de uma situação de incêndio, como se estivessem paralisadas nos primeiros minutos, não acreditando que estejam sendo envolvidas numa situação de risco grave (ARAÚJO, 2008, p.95).

A NR10 - Segurança em Instalações e Serviços em Eletricidade, coloca que as ações de emergência que envolvam as instalações ou serviços com eletricidade devem constar do plano de emergência (BRASIL, 2016b). Embora os textos normativos da NR12 - Máquinas e equipamentos, NR13 - Caldeiras, vasos de pressão e tubulações e NR14 - Fornos, descritos por Brasil (2018c), Brasil (2018d) e Brasil (1983) não apresentem uma diretriz objetiva quanto às ações de emergência, estas ações devem ser identificadas a partir procedimentos de emergência constantes dos manuais das máquinas e equipamentos, conforme NR12 (BRASIL, 2018c) e, junto com outros dados/levantamentos, devem ser contemplados nos planos de emergência.

$\mathrm{O}$ atendimento à emergência real tende a ser uma eventualidade, todavia, é esperado que os treinamentos e simulados se incorporem a rotina do brigadista, ainda que de modo intermitente. Nesse sentido, recomenda-se a aplicação de uma abordagem ergonômica sobre as atividades desempenhadas. Materiais muito pesados, grandes, sem pega, por exemplo, podem exigir esforços desnecessários e posturas inadequadas, inviabilizando que as tarefas sejam executadas com segurança e desempenho eficiente, tal como colocado pela NR 17 - Ergonomia (BRASIL, 2018e).

Para empresas que, por exemplo, armazenem líquidos inflamáveis e/ou combustíveis acima de $10 \mathrm{~m}^{3}$, a NR 20 - Segurança e Saúde com Inflamáveis e Combustíveis determina, dentre outras, que no plano de resposta deverá constar a designação dos brigadistas responsáveis por cada ação e seus substitutos (BRASIL, 2018f), estabelece ainda uma preparação para uma possível atuação mais abrangente, determinando que:

Nos casos em que os resultados das análises de riscos indiquem a possibilidade de ocorrência de um acidente cujas consequências ultrapassem os limites da instalação, o empregador deve incorporar no plano de emergência ações que visem à proteção da comunidade circunvizinha, estabelecendo mecanismos de comunicação e alerta, de isolamento da área atingida e de acionamento das autoridades públicas (BRASIL, 2018d, p. 9).

A NR 23 - Proteção contra Incêndios dispõe que "todos os empregadores devem adotar medidas de prevenção de incêndio, em conformidade com a legislação estadual e as normas técnicas aplicáveis" (BRASIL, 2011b, p. 1). Ao 
fazer o percurso investigativo na direção dessa legislação estadual e das normas técnicas, verifica-se que as normas dos Corpos de Bombeiros dos Estados, do Distrito Federal e as Normas da Associação Brasileira de Normas Técnicas (ABNT) constituem os requisitos normativos a serem adotados para a formação das brigadas de incêndio.

O atendimento a uma emergência real pode levar o brigadista a uma contaminação de suas vestimentas, assim, torna-se relevante atentar para o fato de que a NR 24 - Condições Sanitárias e de Conforto nos Locais de Trabalho estabelece, por exemplo, a necessidade de chuveiros para higiene pessoal nos trabalhos com exposição a substâncias tóxicas, irritantes, dentre outras (BRASIL, 1993).Todavia, é preciso estabelecer um procedimento para retirada das vestimentas contaminadas e sua higienização (Brasil, 2018a) com vistas, por exemplo, a evitar a contaminação de pessoas não envolvidas na emergência.

Quanto aos resíduos, não há qualquer disposição objetiva no texto normativo da NR 25 - Resíduos Industriais, quanto a uma ação emergencial, no entanto a norma determina que haja todo um gerenciamento que envolve a coleta, transporte, armazenamento, dentre outros, e, para cada uma dessas etapas, é preciso adotar ações para proteção dos trabalhadores (BRASIL, 2011c). Chama-se atenção justamente para possíveis falhas nesse gerenciamento, especificamente, situações que envolvam resíduos perigosos e que possam demandar uma atuação da brigada. Nesse sentido, torna-se relevante considerar esses possíveis cenários.

A NR 26 - Sinalização de Segurança (BRASIL, 2015) também não aponta uma ação específica da brigada, entretanto, cabe chamar atenção principalmente para possíveis emergências envolvendo produtos químicos. Nestes casos, para prestação de primeiros socorros ou proteção ambiental de modo mais assertivo, é fundamental que a brigada conheça os produtos utilizados na planta. Nesse contexto, segundo a NR 26 (BRASIL, 2015, p. 2), " o fabricante ou, no caso de importação, o fornecedor no mercado nacional, deve elaborar e tornar disponível ficha com dados de segurança do produto químico para todo produto químico classificado como perigoso."

A NR 33 - Segurança e Saúde no Trabalhos em Espaços Confinados (BRASIL, 2012 , p. 5), dentre outras recomendações, estabelece que "a capacitação da equipe de salvamento deve contemplar todos os possíveis cenários de acidentes identificados na análise de risco". Quanto a atuação em altura, a NR 35 Trabalho em Altura (BRASIL, 2016c, p. 6) determina que "as ações de resposta às emergências que envolvam o trabalho em altura devem constar do plano de emergência da empresa". Assim, é preciso que o responsável pela brigada de incêndio da planta fique atento ao fato de que cenários envolvendo altura e confinamento, dentre outros, irão requerer treinamentos específicos.

\section{PROCEDIMENTO - DEFINIÇÃO DE RECURSOS E OUTRAS PROVIDÊNCIAS}

Estabelecidos os cenários emergenciais, a preparação para atuação da brigada envolve o levantamento dos materiais a serem utilizados, dentre eles, a proteção individual, proteção coletiva, equipamentos, ferramentas, dentre outros. Quanto à proteção do brigadista, a NR6 - Equipamento de Proteção Individual - determina que: 
Compete ao Serviço Especializado em Engenharia de Segurança e em Medicina do Trabalho - SESMT, ouvida a Comissão Interna de Prevenção de Acidentes e trabalhadores usuários, recomendar ao empregador o EPI adequado ao risco existente em determinada atividade. Nas empresas desobrigadas a constituir SESMT, cabe ao empregador selecionar o EPI adequado ao risco, mediante orientação de profissional tecnicamente habilitado, ouvida a CIPA, ou, na falta desta, o designado e trabalhadores usuários. (BRASIL, 2018a, p. 1)

A especificação dos Equipamentos de Proteção Individual (EPI) é uma tarefa que envolve responsabilidade técnica, assim, uma especificação incorreta pode levar a uma exposição do brigadista a diversos agentes de risco, capazes de comprometer sua saúde e segurança, bem como, a contenção da emergência. Cabe ainda ressaltar outros aspectos que precisam ser observados, tais como, o treinamento para uso correto de cada equipamento nas diversas situações, de modo a evitar escolha/uso inadequado por parte dos brigadistas, tal como identificado por Baumgart et al. (2017).

Quanto aos demais equipamentos e ferramentas, é preciso muita atenção no que se refere à explosividade. Segundo a NR 10, uma atmosfera explosiva consiste em uma "mistura com o ar, sob condições atmosféricas, de substâncias inflamáveis na forma de gás, vapor, névoa, poeira ou fibras, na qual após a ignição, a combustão se propaga" (BRASIL, 2016b, p. 8). Diversas situações relacionadas com o armazenamento e transferências de líquidos inflamáveis, armazenamento e movimentação de gases, processamento de grãos - que geram poeiras orgânicas - dentre outras, podem dar origem a formação de atmosferas explosivas.

Essa condição atmosférica pode resultar tanto do processo normal de operação de uma planta - dando origem as chamadas áreas classificadas quanto de situações desencadeadas por falhas operacionais ou acidentes. Em situações emergenciais, tal como um derramamento de líquido combustível, respeitados os volumes e características dos produtos envolvidos, atmosferas explosivas poderão ser formadas. Assim, a partir da NR 10, verifica-se que os equipamentos como rádios de comunicação, lanternas, geradores de energia, dentre outros, comumente utilizados na contenção de uma emergência, devem ser intrinsecamente seguros (BRASIL, 2016b), ou seja:

[...] equipamento que não libera energia elétrica ou térmica suficientes para, em condições normais ou anormais, causar a ignição de uma dada atmosfera explosiva, conforme expresso no certificado de conformidade do equipamento. (BRASIL, 2006, p. 9).

Diante do exposto, é preciso que o responsável pela brigada de incêndio da planta esteja atento aos requisitos de especificação dos materiais, especialmente dos elétricos/eletrônicos. Assim, chama-se atenção que para o fato de que uma análise de risco da planta permite identificar os cenários emergenciais, todavia, identificados os cenários, tem-se a necessidade de realizar análises de risco sobre todas as ações/procedimentos que compõem as estratégias de contenção. 
A NBR 14276 estabelece a necessidade de, internamente, tornar público a composição da brigada, de modo que os brigadistas possam ser facilmente localizados, identificados e acionados; devem utilizar identificação que os destaquem dos demais trabalhadores, bem como, havendo mais de um pavimento ou setor, deverá ser estabelecido um sistema de comunicação entre eles (ASSOCIAÇÃO BRASILEIRA DE NORMAS TÉCNICAS, 2006).

Embora a NR 33 e a NR 35, dentre outras, estabeleçam a realização de simulado com periodicidade mínima anual (BRASIL, 2006; BRASIL, 2012), considera-se razoável recomendar que o responsável pela brigada de incêndio realize estudos voltados para subsidiar a elaboração de um plano de simulados adequado às especificidades da planta e às necessidades da equipe de resposta, respeitadas as exigências normativas. Por fim, o responsável pela brigada de incêndio da planta deverá emitir o Atestado de brigada de incêndio da planta, certificando que a brigada está de acordo com a NBR 14276 e com a NBR 15219 (ASSOCIAÇÃO BRASILEIRA DE NORMAS TÉCNICAS, 2006).

\section{CONCLUSÕES}

A NBR 14276 e a NBR 15219 constituem os principais instrumentos normativos para implantação e atuação das brigadas de incêndio, todavia, se as Normas Regulamentadoras não forem consideradas, algumas lacunas técniconormativas poderão comprometer a atuação das equipes de resposta. A diretriz elaborada para implantação das brigadas de incêndio, composta por três procedimentos, atende ao objetivo proposto, porém apresenta algumas limitações, pois, devido à complexidade e à extensão do tema, não dá conta de colocar, num único documento, todos os requisitos normativos identificados na análise exploratória. 


\title{
Integrated systems of environmental management, safety and occupational health: a guideline for the implantation of fire brigades in industrial plants
}

\begin{abstract}
In industrial establishments there is a diversity of operations that can lead to the occurrence of events with undesirable consequences for the environment, workers and society. In this sense, the need to guarantee the safety of production processes, among other necessities, has led to the adoption of Integrated Systems of Environmental Management, Safety and Occupational Health, consequently, to the implementation of fire brigades. Organizing a brigade is a complex task, since Standard NBR 14276 of the Brazilian Association of Technical Norms does not make reference to the Regulatory Norms (NR) the Secretary of Labor of the Ministry of Economy, except for NR 6 - Individual Protection, being for each professional to perceive the interfaces which need to be considered. Thus, this research aimed to present a guideline for the implementation of fire brigades in industrial plants, without exhausting the subject. NBR 14276 was analyzed and taken as the basis for guideline construction. An exploratory analysis of the Regulatory Norms was carried out in order to identify the normative aspects that could interfere in the implantation and/or action of the fire brigades. Thus, it was verified that NBR 14276 and NBR 15219 are the main normative instruments to be used for the implementation of fire brigades, however, if the Regulatory Norms are not considered, some technical and normative shortcomings may compromise the performance of the response teams. The elaborated guideline, composed of three procedures, meets the proposed objective, but presents some limitations due to the complexity and the extension of the theme.
\end{abstract}

KEYWORDS: Regulatory norm. Emergency plan. Risk analysis 


\section{REFERÊNCIAS}

ALMEIDA, A.K.; FRANZOLO, C.R.G. Projetos de Proteção e Combate a Incêndios: Segurança Como Requisito Fundamental. UNICIÊNCIAS, Cuiabá, v.1, n.1, p.67-71. 2015.

AMORIM, C. M. M.; LIBRELOTTO, L. I.; FERROLI, P. C. M. Gestão ambiental: estudo de caso aplicado numa empresa do setor automobilístico. R. gest. sust. ambient., Florianopolis, v. 4, n. 1, p. 313 - 331, abr./set.2015. crossref

ARAUJO. J.M.F. Comportamento humano em incêndios. In: SEITO, A.I. (Coord.) et al. A Segurança Contra Incêndio no Brasil. São Paulo: Projeto Editora, 2008. p. 379-409.Disponível em: <http://www.ccb.policiamilitar.sp.gov.br/icb/wpcontent/uploads/2017/02/aseguranca_contra_incendio_no_brasil.pdf $>$. Acesso em: 11 jan. 2019.

ASSOCIAÇÃO BRASILEIRA DE NORMAS TÉCNICAS. NBR14276: Brigada de incêndio - requisitos. Rio de Janeiro, 2006.

ASSOCIAÇÃO BRASILEIRA DE NORMAS TÉCNICAS. NBR15219: Plano de emergência contra incêndio - requisitos. Rio de Janeiro, 2005.

BAUMGART, B.Z.; MACEDO, A.B.T.; BORTOLETTI, A.P.G.; SOUZA, S.B.C. Riscos ocupacionais e equipamentos de proteção individual em bombeiros da Brigada Militar. Ciência \& Saúde, Porto Alegre, v.10, n.1, p.28-33. 2017. crossref

BRASIL. Ministério do Trabalho. Norma Regulamentadora № 14 - Fornos. Brasília, 1983. Disponível em:

<https://enit.trabalho.gov.br/portal/images/Arquivos_SST/SST_NR/NR-14.pdf>. Acesso em 03 jan. 2019.

BRASIL. Ministério do Trabalho. Norma Regulamentadora № 24 - Condições Sanitárias e de Conforto nos Locais de Trabalho. Brasília, 1993. Disponível em: <https://enit.trabalho.gov.br/portal/images/Arquivos_SST/SST_NR/NR-24.pdf>. Acesso em 03 jan. 2019.

BRASIL. Ministério do Trabalho. Norma Regulamentadora № 1 - Disposições Gerais. Brasília, 2009. Disponível em: <https://enit.trabalho.gov.br/portal/images/Arquivos_SST/SST_NR/NR-01.pdf>. Acesso em 03 jan. 2019. 
BRASIL. Ministério do Trabalho. Norma Regulamentadora № 5 - Comissão Interna de Prevenção de Acidentes - CIPA. Brasília, 2011a. Disponível em: <https://enit.trabalho.gov.br/portal/images/Arquivos_SST/SST_NR/NR-05.pdf>. Acesso em Acesso em 03 jan. 2019.

BRASIL. Ministério do Trabalho. Norma Regulamentadora № 23 - Proteção contra Incêndios. Brasília, 2011b. Disponível em:

<https://enit.trabalho.gov.br/portal/images/Arquivos_SST/SST_NR/NR-23.pdf>. Acesso em Acesso em 03 jan. 2019.

BRASIL. Ministério do Trabalho. Norma Regulamentadora № 25 - Resíduos Industriais. Brasília, 2011c. Disponível em:

<https://enit.trabalho.gov.br/portal/images/Arquivos_SST/SST_NR/NR-25.pdf>. Acesso em Acesso em 03 jan. 2019.

BRASIL. Ministério do Trabalho. Norma Regulamentadora № 33 - Segurança e Saúde nos Trabalhos em Espaços Confinados. Brasília, 2012. Disponível em: <https://enit.trabalho.gov.br/portal/images/Arquivos_SST/SST_NR/NR-33.pdf>. Acesso em Acesso em 03 jan. 2019.

BRASIL. Ministério do Trabalho. Norma Regulamentadora № 26 - Sinalização de Segurança. Brasília, 2015. Disponível em:

<https://enit.trabalho.gov.br/portal/images/Arquivos_SST/SST_NR/NR-26.pdf>. Acesso em 03 jan. 2019.

BRASIL. Ministério do Trabalho. Norma Regulamentadora № 4 - Serviços Especializados em Engenharia de Segurança e em Medicina do Trabalho. Brasília, 2016a. Disponível em:

<https://enit.trabalho.gov.br/portal/images/Arquivos_SST/SST_NR/NR-04.pdf>. Acesso em 03 jan. 2019.

BRASIL. Ministério do Trabalho. Norma Regulamentadora № 10 - Segurança em Instalações e Serviços em Eletricidade. Brasília, 2016b. Disponível em:

<https://enit.trabalho.gov.br/portal/images/Arquivos_SST/SST_NR/NR-10.pdf>. Acesso em 03 jan. 2019.

BRASIL. Ministério do Trabalho. Norma Regulamentadora № 35 - Trabalho em Altura . Brasília, 2016c. Disponível em:

<https://enit.trabalho.gov.br/portal/images/Arquivos_SST/SST_NR/NR-35.pdf>. Acesso em 03 jan. 2019. 
BRASIL. Ministério do Trabalho. Norma Regulamentadora № 9 - Programa de Prevenção de Riscos Ambientais. Brasília, 2017. Disponível em: <https://enit.trabalho.gov.br/portal/images/Arquivos_SST/SST_NR/NR-09.pdf >. Acesso em 03 jan. 2019.

BRASIL. Ministério do Trabalho. Norma Regulamentadora № 6 - Equipamento de Proteção Individual - EPI. Brasília, 2018a. Disponível em: <https://enit.trabalho.gov.br/portal/images/Arquivos_SST/SST_NR/NR-06.pdf>. Acesso em 03 jan. 2019.

BRASIL. Ministério do Trabalho. Norma Regulamentadora № 7 - Programa de Controle Médico de Saúde Ocupacional. Brasília, 2018b. Disponível em: <https://enit.trabalho.gov.br/portal/images/Arquivos_SST/SST_NR/NR-07.pdf>. Acesso em 03 jan. 2019.

BRASIL. Ministério do Trabalho. Norma Regulamentadora № 12 - Segurança no Trabalho em Máquinas e Equipamentos. Brasília, 2018c. Disponível em: < https://enit.trabalho.gov.br/portal/images/Arquivos_SST/SST_NR/NR-12.pdf>. Acesso em 03 jan. 2019.

BRASIL. Ministério do Trabalho. Norma Regulamentadora № 13 - Caldeiras, Vasos de Pressão, Tubulações e Tanques Metálicos de Armazenamento. Brasília, 2018d. Disponível em:

<https://enit.trabalho.gov.br/portal/images/Arquivos_SST/SST_NR/NR-13.pdf_. Acesso em 03 jan. 2019.

BRASIL. Ministério do Trabalho. Norma Regulamentadora № 17 - Ergonomia. Brasília, 2018e. Disponível em:

<https://enit.trabalho.gov.br/portal/images/Arquivos_SST/SST_NR/NR-17.pdf>. Acesso em 03 jan. 2019.

BRASIL. Ministério do Trabalho. Norma Regulamentadora № 20 - Segurança e Saúde no Trabalho com Inflamáveis e Combustíveis. Brasília, 2018f. Disponível em: <https://enit.trabalho.gov.br/portal/images/Arquivos_SST/SST_NR/NR20.pdf>. Acesso em 03 jan. 2019.

CAMILO JÚNIOR, A.B.; LEITE, W.C. Brigadas de Incêndio. In: SEITO, A.I. (Coord.) et al. A Segurança Contra Incêndio no Brasil. São Paulo: Projeto Editora, 2008. p. 379-409.Disponível em: <http://www.ccb.policiamilitar.sp.gov.br/icb/wpcontent/uploads/2017/02/aseguranca_contra_incendio_no_brasil.pdf $>$. Acesso em: 11 jan. 2019. 
DUARTE, D.; PIRES, T.A.C.; SILVA, J.J.R; OLIVEIRA, M.M. Gerenciamento dos Riscos de Incêndio. In: SEITO, A.I. (Coord.) et al. A Segurança Contra Incêndio no Brasil. São Paulo: Projeto Editora, 2008. p. 379-409.Disponível em:

$<$ http://www.ccb.policiamilitar.sp.gov.br/icb/wpcontent/uploads/2017/02/aseguranca_contra_incendio_no_brasil.pdf $>$. Acesso em: 11 jan. 2019.

ESPÍRITO SANTO. NT07: Brigadas de incêndio, Primeiros Socorros ou Socorros de Urgência, Salva Vidas ou Guarda Vidas: procedimentos para formação, treinamento, reciclagem e cadastramento de empresas. Vitória, 2016. Disponível em: <https://cb.es.gov.br/Media/CBMES/PDF's/CAT/Normas\%20T\%C3\%A9cnicas/12 \%20-\%20NT\%2007-2016.pdf> Acesso em: 26 dez. 2018.

KREUZ, D. FROEHLICH, C. Implementação do sistema de gestão ambiental na empresa $A B C$ do setor coureiro do Vale do Sinos. Estudo \& Debate, Lajeado, v. 25, n. 1, p. 61-85, 2018. Disponível em: < http://univates.br/revistas/index.php/estudoedebate/article/view/1389/1296>. Acesso em 03 jan. 2019.

MENDES, A.R.; TEIXEIRA, V.C. MEDIDAS DE SEGURANÇA CONTRA INCÊNDIO: Estudo de caso em uma edificação residencial multifamiliar. Revista TécnicoCientífica do CREA-PR, Curitiba, n.6, p.01-17. 2017. Disponível em: $<$ http://creaprw16.creapr.org.br/revista/sistema/index.php/revista/article/view/165/117>. Acesso em: 11 jan. 2019.

PACO, E.S.; MOREIRA, H.L.: Segurança em indústrias de couro. Emergência, Novo Hamburgo, v.1, p.45-52. 2016.Disponível em:

<https://www.researchgate.net/publication/292607224_Seguranca_em_industri as_de_couro>. Acesso em: 11 jan. 2019.

PETER FILHO, A. I. O. Análise da integração dos sistemas de gestão ambiental, de saúde e segurança do trabalho e da qualidade numa pequena empresa da construção civil. Brazilian Applied Science Review. Curitiba, v. 2, n. 5, p. 15401552, out./dez. 2018.Disponível em: <http://brjd.com.br/index.php/BASR/article/view/541/465>. Acesso em:10 jan. 2019.

POLTRONIERI, C.F.; GEROLAMO, M.C.; CARPINETTI, L.C.R. Um instrumento para a avaliação de sistemas de gestão integrados. Gestão \& Produção, São Carlos, v. 4, n. 4, jan. 2017. Disponível em: < http://www.scielo.br/pdf/gp/v24n4/0104-530Xgp-0104-530X1697-14.pdf >. Acesso em:12 dez. 2018. 
SEIFFERT, M.E.B. Sistemas de gestão ambiental (ISSO 14001) e saúde e segurança ocupacional (OSHAS 18001): vantagens da implantação integrada.

2.ed. São Paulo: Atlas, 2010.

SILVA, A.T.Q.; CARMO, S.K.S.; CAMPOS, R.J. Medidas de prevenção e proteção em caso de incêndios criminosos em edificações. Revista Brasileira de Criminalística, Brasília, v.7, n.1, p.32-43. 2018.Disponível em:

$<$ http://peritosoficiais.com.br/ojs/index.php/rbc/article/view/192/pdf>. Acesso em: 07 jan. 2019. crossref

D'ÁVILA, W.P.S; CAMPOS, T.A.O. Sistemas integrados de gestão ambiental, segurança e saúde ocupacional: uma diretriz para implantação de brigadas de incêndio em plantas industriais. R. Gest. Industr., Ponta Grossa, v. 16, n. 1, p. 145-163, Jan./Mar. 2020. Disponível em: https://periodicos.utfpr.edu.br/revistagi. Correspondência:

Wilson Pimenta da Silva D’Ávila

Rua Pastor João Pedro da Silva, número 122, apto 1203B, Ataíde, Vila Velha, Espírito Santo, Brasil. CEP $29119-021$.

Direito autoral: Este artigo está licenciado sob os termos da Licença Creative Commons-Atribuição 4.0

Internacional.

\section{(c) (1)}

